Journal of Applied Pharmaceutical Science Vol. 5 (08), pp. 054-060, August, 2015

Available online at http://www.japsonline.com

DOI: $10.7324 /$ JAPS.2015.50809

ISSN 2231-3354 (cc)) BY-NC-SA

\title{
Comparative in vitro dissolution of commercially available sustained release nifedipine tablet brands in the Kumasi Metropolis, Ghana
}

\author{
Christina Osei-Asare, Samuel Lugrie Kipo, Kwabena Ofori-Kwakye*, Mariam El Boakye-Gyasi \\ Department of Pharmaceutics, Faculty of Pharmacy and Pharmaceutical Sciences, College of Health Sciences, Kwame Nkrumah University of Science and \\ Technology, Kumasi, Ghana.
}

\begin{tabular}{l} 
ARTICLE INFO \\
\hline Article history: \\
Received on: $18 / 05 / 2015$ \\
Revised on: 07/06/2015 \\
Accepted on: 09/06/2015 \\
Available online: $28 / 08 / 2015$ \\
\hline Key words: \\
Nifedipine; sustained release; \\
in vitro dissolution; drug \\
substitution; similarity factor; \\
difference factor
\end{tabular}

\begin{abstract}
The aim of this study was to assess the dissolution properties of twelve sustained release (SR) nifedipine tablet brands, including $20 \mathrm{mg}$ and $30 \mathrm{mg}$ innovator brands, for possible generic substitution. The tablet brands were purchased from retail pharmacies in the Kumasi Metropolis, Ghana. The weight uniformity, drug content and in vitro dissolution of the tablets in phosphate buffer $\mathrm{pH} 6.8$ were evaluated. The dissolution data were compared using the similarity $\left(\mathrm{f}_{2}\right)$ and difference $\left(\mathrm{f}_{1}\right)$ factors, and the USP acceptance criteria for SR tablets. The kinetics of drug release from the tablets was also evaluated. All the brands passed the weight uniformity test. Nine brands (75\%) passed the drug content test while three brands $(25 \%)$ failed. The two innovator nifedipine SR brands passed all the tests undertaken. Comparison of the dissolution data using $\mathrm{f}_{1}$ and $\mathrm{f}_{2}$ showed that all three $30 \mathrm{mg}$ nifedipine SR brands were dissimilar to the innovator brand. Also, two $20 \mathrm{mg}$ nifedipine SR brands $(28.6 \%)$ were similar or bioequivalent with the innovator $20 \mathrm{mg}$ brand while five brands $(71.4 \%)$ were dissimilar. Three (75\%) $30 \mathrm{mg}$ and four (50\%) $20 \mathrm{mg}$ nifedipine SR brands exhibited appropriate drug release profiles based on the USP acceptance criteria. Drug release from the twelve tablet brands mostly followed the Higuchi kinetic model $(58.3 \%)$ followed by the Hixson-Crowell model (16.7 \%). Only one brand (N7) exhibited constant drug release kinetics. Results from the study have shown that switching or substituting brands of SR nifedipine for patients should be guided by a critical assessment of the dissolution data using appropriate evaluation techniques.
\end{abstract}

\section{INTRODUCTION}

Hypertension is a major public health problem worldwide with its attendant high morbidity and mortality. Almost a billion of the world's adult population exhibited signs and symptoms of hypertension by the year 2000 (Burt et al., 1995). In Ghana, studies have confirmed the high prevalence of the disease with rather low detection, control and treatment rates (Amoah 2003; Cappuccio et al., 2004; Addo et al., 2006). The disease is generally managed through medication use and/or lifestyle changes. Nifedipine [Dimethyl-2,6-methyl-4-)2nitrophenyl)-1, 4-dihydropyridine-3, 5-dicarboxylate] is a calcium channel blocking agent which is commonly employed in the management of systemic hypertension and angina pectoris (Simon and Levenson, 2003). Nifedipine has also been found useful in conditions such as premature labour, Reynauld's disease and spasms of the oesophagus. Topical nifedipine is also

\footnotetext{
* Corresponding Author

Email: koforikwakye@yahoo.com
}

an effective remedy for anal fissures (Ezri and Susmallian, 2003). In a recent study in Ghana, nifedipine SR was found to be the most popular extended release antihypertensive medication by hypertensive patients and prescribers (Osei-Asare, 2013). Sustained or extended release formulations are ideally suited for the management of hypertension due to better tolerance by patients, reduction in the incidence and severity of untoward sideeffects and improvement in patient compliance leading to better treatment outcomes. On the other hand, the use of immediaterelease nifedipine oral formulations in hypertension management have been associated with rapid rise in drug plasma concentration with consequential increase in heart rate and drug-specific adverse side-effects (Soons et al, 1992). Hence, controlled release formulations of nifedipine are generally preferred to immediaterelease formulations for hypertension management. Nifedipine $(\mathrm{pka}=3.93)$ is a Biopharmaceutics Classification System (BCS) Class II drug with very poor solubility in water (Friedrich et al., 2005; Sweetman, 2009) and the absorption of the drug from the gastrointestinal tract is limited by its rate of dissolution. 
Dissolution testing is an important tool employed in pharmaceutical development and in quality evaluation of solid dosage formulations (Nagai et al., 2011), especially poorly soluble drugs. Dissolution testing is also used as a surrogate for in vivo drug release and bioavailability of drugs.

The pharmaceutical quality and dissolution properties of commercial nifedipine tablet brands have been a major concern to researchers and healthcare professionals. As a result, several studies have been undertaken to assess the pharmaceutical and biopharmaceutical quality of nifedipine SR formulations available to the healthcare delivery system of various countries. The pharmaceutical quality evaluation of ten commercial brands of 20 mg nifedipine SR tablets in Kano, Nigeria showed that only four were pharmaceutically equivalent (Oyeniyi and Ayorinde, 2012). The dissolution properties of prolonged release nifedipine tablets sampled on the Belgian market indicated that the brands were dissimilar and were therefore not interchangeable (De Braekeleer et al., 2009). Also, in India, the release profiles of four marketed extended release nifedipine tablets was compared using mathematical models and were found to be unsuitable to be switched from one brand to another (Deshpande et al., 2013). The dissolution of nifedipine tablets produced in five different factories in China was evaluated by Wang et al. (2012) and found to comply with standards of the Chinese Pharmacopoeia but failed to meet the specifications of both the British Pharmacopoeia and the United States Pharmacopoeia. Another recent study on the pharmaceutical quality of extended release expired and unexpired nifedipine tablets sampled from Estonia and the Russian Federation found the dissolution rates of the unexpired brands from the two countries to be comparable with the observation that the expired products achieved faster release than the unexpired ones (Teder et al., 2013).

The aim of the current study was to evaluate the dissolution properties of commercial nifedipine SR brands available to the healthcare delivery system in the Kumasi Metropolis of Ghana. The dissolution data would be compared using appropriate methods to ascertain the similarity/bioequivalence or otherwise of the generic brands against $20 \mathrm{mg}$ and $30 \mathrm{mg}$ nifedipine SR innovator brands. The kinetics of drug release from the tablet brands would also be evaluated.

\section{MATERIALS AND METHODS}

\section{Materials}

USP Nifedipine reference sample (RS) was a gift from Sharon Bio-Medicine Ltd (Taloja, Mumbai, India). Twelve (12) sustained release (SR) nifedipine tablet brands were purchased from selected community and hospital pharmacies within the Kumasi Metropolis. The product information of the nifedipine tablet brands are presented in Table 1. Dibasic sodium phosphate, citric acid, phosphoric acid, sodium lauryl suphate, acetonitrile, methanol, methanolic potassium hydrochloride, sulphuric acid, sodium nitrite, naphthylethylene diamine dihydrochlorate, ammonium sulpahamate, 2-methyl-2-propanol, perchloric acid, cerium sulphate, ferroin $\mathrm{R}$ indicator and other analytical grade reagents were imported from Merck Specialties Private Ltd, (Mumbai, India) and were obtained from the chemical store of Ernest Chemists Ltd. (Manufacturing Division) Tema, Ghana.

\section{Uniformity of weight of tablets}

Twenty tablets of each brand of nifedipine SR were selected, weighed individually and the mean tablet weight $( \pm S$. D.) determined. The percent deviation of each tablet from the mean weight was then determined. Based on the weight deviations, an assessment was made as to whether the tablet brand passed or failed the British Pharmacopoeia Uniformity of weight test.

\section{Determination of drug content}

Twenty five (25) tablets of nifedipine SR $20 \mathrm{mg}$ and twenty (20) tablets of nifedipine SR $30 \mathrm{mg}$ were randomly selected from the respective brands, weighed and finely powdered with the aid of a porcelain mortar and pestle. Nifedipine powder equivalent to $420 \mathrm{mg}$ nifedipine from each tablet brand was transferred to a $250 \mathrm{ml}$ volumetric flask containing $130 \mathrm{ml}$ water. The mixture was shaken in an orbital shaker and acetonitrile and methanol (1:1) solution was added to the volume and stirred for 30 minutes. The resultant solution was centrifuged to obtain the stock solution. Three milliliters of the stock solution was transferred into a $50 \mathrm{ml}$ volumetric flask and diluted with acetonitrile and methanol (1:1) solution to volume. The solution was mixed and filtered with Whatman no. 1 filter paper to obtain a solution containing approximately $0.1 \mathrm{mg}$ nifedipine per $\mathrm{ml}$. The content of drug in the filtered samples was determined with an Agilent Technologies 1200 series HPLC equipment (Germany) fitted with Agilent Prep C-18 Scalar column $(4.6 \times 25 \mathrm{~cm}$ analytical column containing L1 packing), a $2.1 \mathrm{~mm}$ x $3 \mathrm{~cm}$ guard column containing L1 packing (Agilent technologies, Germany), a $265 \mathrm{~nm}$ detector and a 4.00 $\mathrm{mm} \times 125 \mathrm{~mm}$ column that contains 3um packing L1. The mobile phase consisted of a mixture of water, acetonitrile and methanol $(2: 1: 1)$ with a flow rate of $1.5 \mathrm{ml} / \mathrm{min}$ and an injection volume of $25 \mu$ l. A column efficiency of not less than 4000 theoretical plates with tailing factor of not more than 1.5 was set. The HPLC primary data was entered into Microsoft Excel 2007 professional Edition and used to calculate the content of nifedipine in the various tablet brands.

\section{Identification tests and quality evaluation of nifedipine RS}

Nifedipine RS was subjected to identification tests by way of appearance, solubility (USP, 2007) and colour (BP, 2011) tests. Nifedipine RS was also analysed for the drug content using a double titration method (BP, 2011) and the loss on drying was similarly evaluated (USP, 2007).

\section{In vitro dissolution studies}

In vitro dissolution of nifedipine SR tablet brands was undertaken using an Erweka dissolution apparatus (Copley 
Scientific, UK). The test was based on the USP test 2 (paddle method). The test conditions were: dissolution media: $900 \mathrm{ml}$ phosphate buffer $\mathrm{pH} 6.8$; paddle speed: $50 \mathrm{rpm}$; temperature: $37 \pm$ $0.5^{\circ} \mathrm{C}$; sampling period: $24 \mathrm{~h}$. At specified time intervals, $8 \mathrm{ml}$ of dissolution medium was withdrawn and replaced with the same volume of fresh dissolution medium. The collected samples were immediately filtered with a Whatman no. 1 filter paper and the amount of drug in the filtered samples was determined using the Agilent Technologies 1200 series HPLC equipment (Germany) mentioned above with the detector set at $350 \mathrm{~nm}$. The mobile phase consisted of acetonitrile and water (70:30) and the chromatographic conditions employed were: injection volume: 25 ul; flow rate: $1.5 \mathrm{ml} / \mathrm{min}$; column efficiency: $\geq 2000$ theoretical plates; and tailing factor: $\leq 1.5$. The percent drug release of each nifedipine SR brand at 3, 6 and $12 \mathrm{~h}$ were determined by entry of the HPLC primary data into Microsoft Excel 2007 professional Edition, and the results compared to the USP (2007) acceptance criteria for nifedipine SR tablets at the three time points.

\section{Comparison of dissolution profiles}

The dissolution data obtained was compared using the model-independent fit factors, namely: difference $\left(\mathrm{f}_{1}\right)$ and similarity $\left(\mathrm{f}_{2}\right)$ factors (Moore and Flanner, 1996; Gohel et al, 2005; Sayar et al, 2008). Two different comparisons were made, one for $20 \mathrm{mg}$ nifedipine SR brands using Adalat 20 as reference sample, and another for $30 \mathrm{mg}$ nifedipine SR brands with Adalat 30 as reference sample.

$$
\begin{gathered}
\mathrm{f}_{1}=\{[\Sigma \mathrm{t}=1 \mathrm{n}|\mathrm{Rt}-\mathrm{Tt}|] /[\Sigma \mathrm{t}=1 \mathrm{n} \mathrm{Rt}]\} \times 100 \\
\mathrm{f}_{2}=50+\log \left\{\left[1+(1 / \mathrm{n}) \sum_{\mathrm{t}=1} * \mathrm{n}\left(\mathrm{R}_{\mathrm{t}}-\mathrm{T}_{\mathrm{t}}\right)^{2}\right]^{-0.5} * 100\right\} ;
\end{gathered}
$$

Where, $\mathrm{n}=$ time points; $\mathrm{R}_{\mathrm{t}}=$ percentage drug dissolved at time $\mathrm{t}$ for the reference product; $\mathrm{Tt}=$ percentage drug dissolved at time $\mathrm{t}$ for the test product. The values of $f_{1}$ ranges from 0 to 15 while $f_{2}$ ranges from 50 to 100 . A test product is similar and hence equivalent to a reference product if $f_{1} \leq 15$ and $f_{2} \geq 50$. Also, two products are dissimilar and hence non-equivalent when $f_{1}>15$ and $\mathrm{f}_{2}<50$.

\section{Kinetics of drug release}

The dissolution data was fitted into five (5) kinetic dissolution models, namely: zero order, first order, Higuchi, Hixson-Crowell and Korsmeyer-Peppas equations (Varelas et al., 1995; Wagner, 1969; Higuchi, 1963; Hixson and Crowell, 1931; Korsmeyer et al., 1983; Peppas, 1985) to evaluate the release kinetics and the mechanism of drug release for the twelve nifedipine SR tablet brands.

\section{Statistical analysis}

The dissolution data was subjected to one-way analysis of variance (ANOVA) followed by Dunnett's multiple comparison test using GraphPad Prism version 5.00 for Windows (GraphPad Software, San Diego California, USA, www.graphpad.com). The dissolution data for $20 \mathrm{mg}$ and $30 \mathrm{mg}$ nifedipine SR tablet brands were compared to their respective innovator brands and differences were considered significant when $\mathrm{p}<0.5$.

\section{RESULTS AND DISCUSSION}

Twelve brands of nifedipine SR tablets were identified in the Kumasi Metropolis of Ghana (Table 1). Four brands were of $30 \mathrm{mg}$ strength while eight were of $20 \mathrm{mg}$ strength. Also, while four brands were manufactured in India, eight were produced in three European countries. None of the samples was manufactured locally in Ghana. Table 2 presents the physical characteristics of the nifedipine tablet brands, namely: shape, colour, nature of surface and type of cavity.

Table 1: Profile of nifedipine SR brands marketed in the Kumasi Metropolis,

\begin{tabular}{|c|c|c|c|c|c|}
\hline 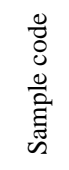 & 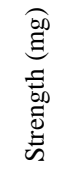 & 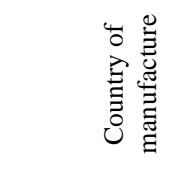 & 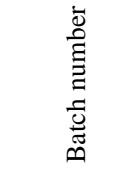 & 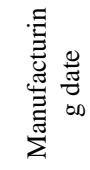 & 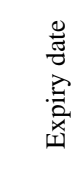 \\
\hline N1 & 30 & Germany & Bxg5jyl & $09 / 12$ & $09 / 15$ \\
\hline $\mathrm{N} 2$ & 30 & Slovenia & Cv4547 & $08 / 12$ & $08 / 15$ \\
\hline N3 & 30 & UK & 310472 & $05 / 11$ & $04 / 14$ \\
\hline $\mathrm{N} 4$ & 30 & India & $19 \mathrm{c} 14$ & 09/12 & $09 / 15$ \\
\hline N5 & 20 & Germany & Bxfg4el & $06 / 12$ & $06 / 15$ \\
\hline N6 & 20 & Slovenia & Vii080 & $09 / 11$ & $09 / 14$ \\
\hline N7 & 20 & UK & 620002 & $01 / 11$ & $12 / 14$ \\
\hline N8 & 20 & Germany & 17016 & $12 / 11$ & $11 / 14$ \\
\hline N9 & 20 & UK & 410267 & $09 / 11$ & $09 / 14$ \\
\hline N10 & 20 & India & Vmo264 & 03/11 & $02 / 14$ \\
\hline N11 & 20 & India & $\mathrm{Nf}-023$ & $06 / 12$ & $07 / 15$ \\
\hline $\mathrm{N} 12$ & 20 & India & E01021 & $08 / 11$ & $08 / 14$ \\
\hline
\end{tabular}
Ghana.

Table 2: Physical characteristics of nifedipine SR tablet brands studied

\begin{tabular}{lllll}
\hline $\begin{array}{c}\text { Sample } \\
\text { code }\end{array}$ & Tablet colour & $\begin{array}{c}\text { Tablet } \\
\text { shape }\end{array}$ & $\begin{array}{c}\text { Nature } \\
\text { of } \\
\text { surface }\end{array}$ & Cavity profile \\
\hline N1 & Brown & Round & Smooth & Normal convex \\
N2 & Brown & Round & Smooth & Normal convex \\
N3 & Pink & Round & Smooth & Shallow and convex \\
N4 & Yellow & Round & Smooth & Shallow and convex \\
N5 & Yellow & Round & Smooth & Bevel convex \\
N6 & Orange & Round & Smooth & Shallow and convex \\
N7 & Golden brown & Oblong & Smooth & Shallow and convex \\
N8 & Golden brown & Round & Smooth & Shallow and convex \\
N9 & Orange & Round & Smooth & Scored, shallow faced \\
N10 & Golden brown & Round & Smooth & Shallow and convex \\
N11 & Golden brown & Round & Smooth & Normal convex \\
N12 & Orange & Round & Smooth & Normal convex \\
\hline
\end{tabular}

Almost all the twelve nifedipine SR brands exhibited unique characteristics that made them different from one another. It was considered important to assess the physical attributes of the tablet brands due to the perceived influence of the physical appearance of tablets such as colour and shape on their effectiveness (de Craen et al., 1996; Khan et al., 2010). Also, changes in the physical appearance of drugs may cause confusion and misunderstanding among patients, especially geriatrics and the uneducated, during generic drugs substitution or switching. Each of the nifedipine SR brands had a shelf-life of three years and the tablets were analysed at least six months before their expiry dates. All the brands studied were duly registered with the Food and Drugs Authority (FDA, Ghana), the statutory medicines regulatory agency in Ghana. Table 3 presents the tablet weight and drug content of the 
nifedipine SR brands. All the brands passed the British Pharmacopoeia (2011) uniformity of weight test. The standard deviation which is a measure of variability or dispersion around the mean weight of the twenty tablets sampled was lowest for brand NI $( \pm 1.35)$ and highest for N12 $( \pm 14.51)$. Thus, brand NI had the best uniformity of weight variation while N12 had the highest dispersion/least clustering of tablet weight around the mean weight and hence the least uniform brand. Variability in tablet weight could be the result of defective formulation and production processes such as poor weighing of active pharmaceutical ingredients and excipients, poor mixing of ingredients and changes in tablet compression force applied. A variation in tablet weight could be an indication of a change in the content of API in the tablet. Nine of the tablet brands achieved a percentage nifedipine content that fell within the prescribed limit of $90-110 \%$ (USP, 2007) while three brands (N2, N8 and N11) failed the test with relatively high drug content values of 113.97 $\%, 111.45 \%$ and $115.47 \%$, respectively (Table 3 ).

Table 3: Average tablet weight and drug content of nifedipine SR tablets studied.

\begin{tabular}{|c|c|c|c|c|}
\hline 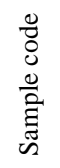 & 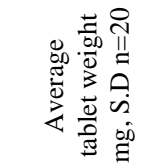 & 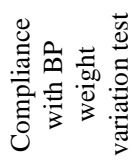 & 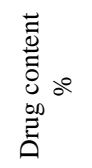 & 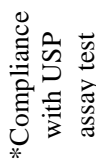 \\
\hline N1 & $298.4 \pm 1.35$ & Passed & 108.40 & Passed \\
\hline $\mathrm{N} 2$ & $416.8 \pm 6.50$ & Passed & 113.97 & Failed \\
\hline N3 & $297.3 \pm 4.84$ & Passed & 98.47 & Passed \\
\hline N4 & $195.2 \pm 2.60$ & Passed & 99.70 & Passed \\
\hline N5 & $84.3 \pm 1.78$ & Passed & 102.02 & Passed \\
\hline N6 & $94.4 \pm 1.46$ & Passed & 107.00 & Passed \\
\hline N7 & $125.5 \pm 1.97$ & Passed & 102.23 & Passed \\
\hline N8 & $181.5 \pm 1.62$ & Passed & 111.45 & Failed \\
\hline N9 & $91.0 \pm 2.09$ & Passed & 101.56 & Passed \\
\hline N10 & $127.5 \pm 1.65$ & Passed & 102.00 & Passed \\
\hline N11 & $155.6 \pm 4.64$ & Passed & 115.47 & Failed \\
\hline N12 & $321.2 \pm 14.81$ & Passed & 101.90 & Passed \\
\hline
\end{tabular}

*Acceptance range: $90-110 \%$

The three brands which failed the test were overdosed and could be considered as substandard brands. The nifedipine reference standard (RS) was analysed to confirm its authenticity and suitability as standard for dissolution testing via recommended pharmacopoeial tests, namely: identification, assay and loss on drying tests. The sample passed the appearance test (formation of yellow crystalline powder) and solubility test (powder practically insoluble in water, freely soluble in acetone, sparingly soluble in ethanol) (USP, 2007), as well as the colour test (formation of intense red colour which persisted for more than 5 minutes) (BP, 2011). Nifedipine RS thus complied with the identification tests specified in both the British Pharmacopoeia and the United States Pharmacopoeia.

The drug content of nifedipine RS was determined to be $101.39 \%$ which was within the acceptable range of $98-102 \%$ for nifedipine (BP, 2011). The loss on drying of $0.5 \%$ obtained for nifedipine RS was in compliance with the specification on loss of drying for the drug (USP, 2007). Nifedipine RS thus complied with all the pharmacopoeial tests undertaken and could therefore be considered as suitable for use as reference standard for in vitro dissolution studies on nifedipine tablet brands.

Figures 1 and 2 show the dissolution profiles of $30 \mathrm{mg}$ strength and $20 \mathrm{mg}$ strength nifedipine SR tablet brands, respectively. Evaluation of the dissolution profiles of solid dosage forms such as tablets, pellets and granules, provides a better characterization of the dissolution properties of the product than single-point dissolution (Shah et al., 1998).

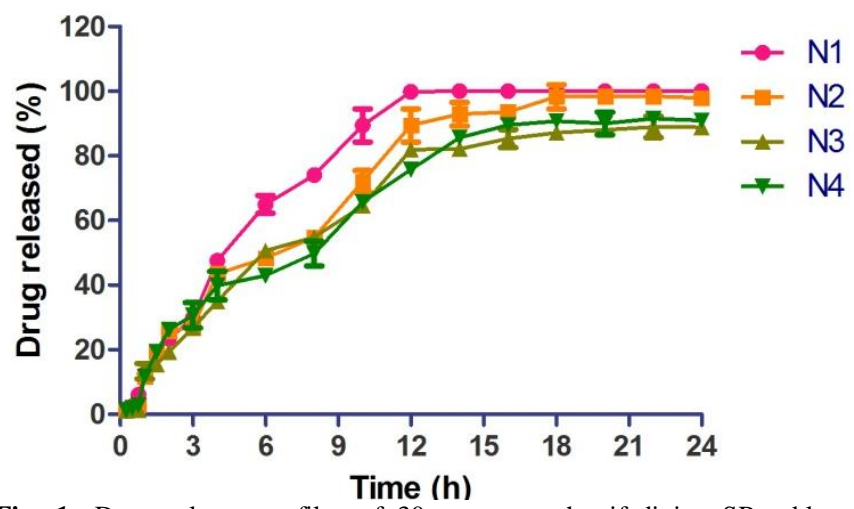

Fig. 1: Drug release profiles of $30 \mathrm{mg}$ strength nifedipine SR tablets in phosphate buffer pH 6.8 (mean \pm S.D., $n=3$ )

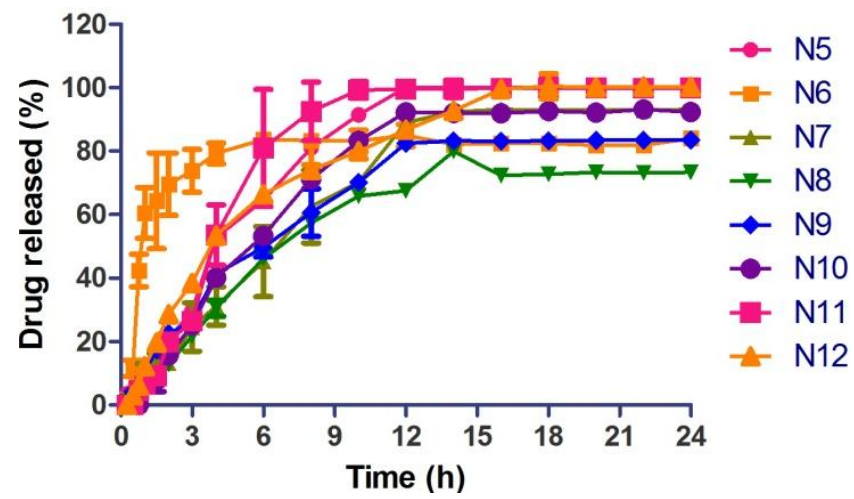

Fig. 2: Drug release profiles of $20 \mathrm{mg}$ strength nifedipine $\mathrm{SR}$ tablets in phosphate buffer $\mathrm{pH} 6.8$ (mean \pm S.D., $\mathrm{n}=3$ )

All the brands, except N6, exhibited typical characteristics of prolonged or extended release solid dosage forms with relatively low initial drug release in aqueous medium $(<15 \%$ drug release in the first $1 \mathrm{~h}$ ) followed by continuous and prolonged release over $24 \mathrm{~h}$. Brand N6, on the other hand, behaved typically as a sustained release dosage form with a fast initial release (approximately $61 \%$ drug release in the first $1 \mathrm{~h}$ ) followed by continuous release over $24 \mathrm{~h}$. The release data of the nifedipine SR tablet preparations in phosphate buffer $\mathrm{pH} 6.8$ based on the USP acceptance criteria for SR tablets are presented in Table 4.

A nifedipine SR formulation is considered to demonstrate the requisite dissolution profiles and hence suitable for use if it satisfies the acceptance criteria of percent drug release at 3 time-points in phosphate buffer pH 6.8 (USP, 2007). The USP (2007) specifies 10-30\% drug release in 3 hours, $40-65 \%$ drug release in 6 hours and $>80 \%$ drug release in 12 hours. Based on 
this specification, three brands (N1, N2 and N3) out of the four nifedipine SR $(30 \mathrm{mg})$ formulations could be considered as equivalent and hence interchangeable. Brand $\mathrm{N} 4$, however, failed two of the three time-points specification.

Table 4: Drug release data of nifedipine SR tablet brands based on USP (2007) acceptance criteria for SR tablets

\begin{tabular}{ccccl}
\hline \multirow{2}{*}{$\begin{array}{l}\text { Sample } \\
\text { code }\end{array}$} & \multicolumn{3}{c}{ Drug release $\%,(\mathrm{n}=6)$} & \multirow{2}{*}{ Remarks } \\
\cline { 2 - 4 } & $3 \mathrm{~h}$ & $6 \mathrm{~h}$ & $12 \mathrm{~h}$ & \\
\hline N1 & 29.78 & 64.98 & 99.85 & Passed \\
N2 & 27.09 & 48.35 & 89.40 & Passed \\
N3 & 26.74 & 50.66 & 81.98 & Passed \\
N4 & 30.62 & 42.94 & 75.72 & Failed \\
N5 & 29.76 & 64.54 & 100.09 & Passed \\
N6 & 73.83 & 83.66 & 84.93 & Failed \\
N7 & 24.59 & 45.23 & 89.02 & Passed \\
N8 & 21.73 & 46.15 & 67.55 & Failed \\
N9 & 26.21 & 49.61 & 82.46 & Passed \\
N10 & 25.18 & 53.39 & 92.27 & Passed \\
N11 & 26.45 & 80.98 & 99.56 & Failed \\
N12 & 38.40 & 66.43 & 86.78 & Failed \\
\hline USP acceptance criteria: $3 \mathrm{~h}: 10-30 \%$ release; $6 \mathrm{~h}: 40-65 \%$ release, $12 \mathrm{~h}:$ \\
$>$ 80 \% release \\
Passed = brands which passed at all three time points \\
Failed = brands which did not pass all three time points
\end{tabular}

Four brands (N5, N7, N9 and N10) out of the eight 20 mg nifedipine SR brands complied with the USP specification on percentage drug release at all the 3 time-points. However, brands N6, N8, N11 and N12 failed the USP (2007) dissolution test by not showing compliance at all the 3 time-points specified. These nifedipine brands have poor release profiles and are therefore unsuitable SR formulations. Thus, based on these acceptance criteria, seven nifedipine SR brands (NI, N2, N3, N5, N7, N9 and N10) passed the test while five brands (N4, N6, N8, N11 and N12) failed the test. Brands N1 and N5 which are innovator brands depicted the highest percentage release at 3, 6 and 12 hours for the $30 \mathrm{mg}$ and $20 \mathrm{mg}$ formulations, respectively. On the other hand, statistical analysis of the dissolution data of both $20 \mathrm{mg}$ and $30 \mathrm{mg}$ nifeipine SR tablet brands using one-way ANOVA followed by Dunnett's multiple comparison test, showed no significant differences $(p>0.05)$ between all the generic brands and their innovator reference brands.

Differences in dissolution profiles of SR tablet brands of the same drug may be due to the physical and chemical properties of the drug substance as well as the product formulation properties (Salomon and Doelker, 1980; El-Arini and Leuenberger, 1995). Some of these physicochemical properties of drugs include $\mathrm{pH}$, particle size, crystalline nature and the polymorphic form. Formulation properties including the nature and amount of polymer, type and amount of excipients, hydration and tablet compression properties also affect the release profiles of solid dosage forms (Bravo et al., 2002). The dissolution of SR nifedipine tablet preparations are also affected by dissolution test conditions (Garbacz et al., 2009).

Tables 5 and 6 show the difference and similarity factors for $30 \mathrm{mg}$ and $20 \mathrm{mg}$ strength nifedipine SR tablets, respectively. This model-independent technique was employed to determine the similarity/equivalence or otherwise of the drug dissolution profiles. The difference factor $f_{1}$ usually has values of $0-15$ and the lower the value the smaller the difference or variation between the dissolution profiles. On the other hand, the similarity factor $\mathrm{f}_{2}$ has values of 50-100, and the higher the value the more similar the dissolution profiles. Thus, two products could be said to be bioequivalent and therefore clinically interchangeable when $\mathrm{f}_{1} \leq$ 15 while $\mathrm{f}_{2} \geq 50$. From the results of the current study, all the three $30 \mathrm{mg}$ strength nifedipine SR tablet brands (N2, N3 and N4) were dissimilar and thus not bioequivalent with the reference brand Adalat 30 (N1). In the case of the $20 \mathrm{mg}$ strength nifedipine SR brands, five brands (N6, N7, N8, N9 and N10) were dissimilar while two brands (N11 and N12) were similar to the reference sample Adalat 20 (N5). Thus, brands $\mathrm{N} 11$ and N12 are bioequivalent with Adalat $20 \mathrm{mg}$ and could therefore be employed as suitable substitutes for the innovator brand. The study has demonstrated that while many generics of nifedipine SR abound in Ghana and other developing countries, there are potential challenges with their dissolution and bioequivalence which could affect their clinical performance and hence limit their use as generic substitutes.

Table 5: Similarity and difference factors for nifedipine SR $30 \mathrm{mg}$ tablet brands.

\begin{tabular}{cccl}
\hline Sample code & $\begin{array}{c}\text { Similarity } \\
\text { factor, } \mathrm{f}_{2}\end{array}$ & $\begin{array}{c}\text { Difference } \\
\text { factor, } \mathrm{f}_{1}\end{array}$ & Remark \\
\hline N2 & 51 & 18 & Dissimilar \\
N3 & 46 & 26 & Dissimilar \\
N4 & 43 & 26 & Dissimilar \\
\hline
\end{tabular}

Reference sample $=$ NI (Adalat 30)

Similar when $\mathrm{f}_{2}=50-100$ and $\mathrm{f}_{1}=0-15$

Dissimilar when $\mathrm{f}_{2}<50$ and $\mathrm{f}_{1}>15$

Table 6: Similarity and difference factors for nifedipine SR $20 \mathrm{mg}$ tablet brands .

\begin{tabular}{cccc}
\hline Sample code & $\begin{array}{c}\text { Similarity } \\
\text { factor, } \mathrm{f}_{2}\end{array}$ & $\begin{array}{c}\text { Difference } \\
\text { factor, } \mathrm{f}_{1}\end{array}$ & *Remark \\
\hline N6 & 25 & 50 & Dissimilar \\
N7 & 45 & 28 & Dissimilar \\
N8 & 39 & 39 & Dissimilar \\
N9 & 47 & 23 & Dissimilar \\
N10 & 55 & 20 & Dissimilar \\
N11 & 58 & 13 & Similar \\
N12 & 59 & 12 & Similar \\
\hline
\end{tabular}

Reference sample $=$ N5 (Adalat 20)

*Similar when $\mathrm{f}_{2}=50-100$ and $\mathrm{f}_{1}=0-15 ;$ Dissimilar when $\mathrm{f}_{2}<50$ and $\mathrm{f}_{1}>15$

The kinetics of drug release from the tablets were studied using five kinetic models of zero order, first order, Higuchi model, Hixson-Crowell model and the Korsmeyer-Peppas model. Kinetics of drug release is employed in formulation development and also as a determinant of mechanism of drug release. The kinetics of drug release from the nifedipine SR brands is presented in Table 7. The kinetic model with the highest correlation coefficient or coefficient of determination $\left(\mathrm{R}^{2}\right)$ provides the best fit for the particular nifedipine SR tablet brand. Drug release from seven (7) of the nifedipine SR brands (N1, N2, N3, N4, N5, N9 and N11) followed the Higuchi kinetic model; two (N8 and N10) followed the Hixson-Crowell model; and one brand (N2) followed the first 
order release kinetics. The only nifedipine SR brand which exhibited constant drug release (zero order kinetics) was brand N7. Thus, the Higuchi model was the dominant kinetic model for majority of the tablet brands. This model signifies that the release of drug from matrices of these tablets was a square root of time dependent process based on Fickian diffusion (Higuchi, 1963).

Table 7: Drug release kinetic parameters of nifedipine SR tablet brands studied

\begin{tabular}{llllll}
\hline \multirow{2}{*}{$\begin{array}{c}\text { Sample } \\
\text { code }\end{array}$} & $\begin{array}{c}\text { Zero } \\
\text { order }\end{array}$ & First order & Higuchi & $\begin{array}{c}\text { Hixson- } \\
\text { Crowell }\end{array}$ & $\begin{array}{c}\text { Korsmeyer- } \\
\text { Peppas }\end{array}$ \\
\cline { 2 - 6 } N1 & 0.9759 & 0.7723 & 0.9885 & 0.8963 & 0.8017 \\
N2 & 0.9598 & 0.8877 & 0.9716 & 0.9420 & 0.8899 \\
N3 & 0.9694 & 0.9559 & 0.9822 & 0.9756 & 0.8493 \\
N4 & 0.9387 & 0.9619 & 0.9740 & 0.9642 & 0.9276 \\
N5 & 0.9694 & 0.9365 & 0.9811 & 0.8639 & 0.6695 \\
N6 & 0.4584 & 0.4593 & 0.6182 & 0.5523 & $* 0.9591$ \\
N7 & 0.9594 & 0.9478 & 0.9386 & 0.9356 & 0.2846 \\
N8 & 0.9691 & 0.9579 & 0.9772 & 0.9837 & 0.7522 \\
N9 & 0.9646 & 0.9807 & 0.9850 & 0.9814 & 0.2614 \\
N10 & 0.9822 & 0.9826 & 0.9785 & 0.9909 & 0.5871 \\
N11 & 0.9070 & 0.6573 & 0.9339 & 0.8292 & 0.5334 \\
N12 & 0.9179 & 0.9862 & 0.9848 & 0.9790 & 0.3013 \\
\hline
\end{tabular}

$*_{n}=$ diffusion coefficient $=1.76$

Brands N8 and N10 showed the best linearity of their plots for the Hixson-Crowell kinetic model with $\mathrm{R}^{2}$ values of 0.9837 and 0.9909 , respectively. For these brands drug release occurs in planes that are parallel to the drug surface if the tablet dimensions diminish proportionally, in such a manner that the initial geometrical form keeps constant all the time (Dash et al., 2010). For brand N2, a first order release kinetic indicates that the velocity of dissolution of the tablet in a liquid is a function of the concentration at the tablet surface (Bravo et al., 2002). Only brand N6 depicted the Korsmeyer-Peppas kinetic model with an $\mathrm{R}^{2}$ value of 0.9561 and $n$ (diffusional coefficient) value of 1.76 . The diffusional coefficient is used to characterize the mechanism of drug release. An ' $n$ ' value of $1.76(n>0.89)$ is indicative of a super case II transport mechanism for brand N6. Diffusional drug release from this tablet brand would occur from a polymeric film (Peppas, 1985). From the results, various nifedipine SR brands followed different kinetic models due possibly to differences in their formulation parameters, such as the type and amount of polymer used and the characteristics of the drug matrices which control the sustained-release mechanism (Siepmann et al., 2000).

\section{CONCLUSION}

The study has demonstrated the variability in the drug release patterns of nifedipine SR brands available in the Kumasi Metropolis of Ghana. Comparison of dissolution profiles using difference and similarity factors showed that three $30 \mathrm{mg}$ nifedipine SR brands were dissimilar to the reference brand, while only two out of seven $20 \mathrm{mg}$ nifedipine SR brands were similar to the reference brand. On the other hand, assessment of dissolution data based on the USP acceptance criteria for SR nifedipine formulations showed that three brands of $30 \mathrm{mg}$ and four brands of $20 \mathrm{mg}$ nifedipine SR possessed appropriate dissolution properties and could be interchanged. The study has shown the need for continuous and comprehensive evaluation of the release profiles of this life-saving medication to ensure that hypertensive patients are provided with good and efficacious medications.

\section{ACKNOWLEDGEMENT}

The authors would like to thank the management and staff of Ernest Chemists Ltd. (Manufacturing Division), Accra, Ghana, for providing the analytical reagents for the study and for allowing the use of their laboratory for the analytical work.

\section{REFERENCES}

Addo J, Amoah AGB, Koram KA. The changing patterns of hypertension in Ghana: a study of four rural communities in the $\mathrm{Ga}$ District. Ethn Dis 2006; 16(4): 894 - 899.

Amoah AG. Hypertension in Ghana: a cross-sectional community prevalence study in greater Accra. Ethn Dis 2003; 13(3): 310 315 .

Bravo SA, Lamas MC, Salomon CJ. In vitro studies of diclofenac sodium controlled-release from biopolymeric hydrophilic matrices. Journal of Pharmacy \& Pharmaceutical Sciences 2002; 5(3): 213-219.

British Pharmacopoeia, 2011. British Pharmacopoeia Commission. Her Majesty's Stationery Office, London.

Burt VL, Whelton P, Roccella EJ, Brown C, Cutler JA, Higgins M, Horan MJ, Labarthe D. Prevalence of hypertension in the US adult population. Results from the Third National Health and Nutrition Examination Survey, 1988-1991. Hypertension, 1995; 25(3): 305 - 313.

Cappuccio FP, Micah FB, Emmett L, Kerry SM, Antwi S, Martin-Peprah R, Phillips OR, Plange-Rhule J, Eastwood JB. Prevalence, detection, management, and control of hypertension in Ashanti, West Africa. Hypertension, 2004; 43(5): 1017-1022.

Dash S, Murthy PN, Nath L, Chowdhury P. Kinetic modeling on drug release from controlled drug delivery systems. Acta. Pol Pharm 2010; 67 (3): 217-223.

De Braekeleer K, Fierens C, Corthout J. Nifedipine preparations on the Belgian market: a comparative study. J Pharm Belg 2009; 64(4): $141-146$.

de Craen AJ, Roos PJ, Leonard de Vries A, Kleijnen J. Effect of colour of drugs: systematic review of perceived effect of drugs and of their effectiveness. BMJ 1996; 313(7072): 1624 - 1626.

Deshpande A, Deshpande S, Lokhandwala H. In vitro release comparison of nifedipine from marketed and prepared controlled release formulations by mathematical modeling. International Journal of Pharma and Bio Sciences, 2013; 4(2): 717 - 726.

El-Arini SK, Leuenberger H. Modeling of drug release from polymer matrices: Effect of drug loading. Int J Pharm 1995; 121 (2): $141-$ 148. DOI:10.1016/0378-5173(94)00418-5

Ezri T, Susmallian S. Topical nifedipine vs. topical glyceryl trinitrate for treatment of chronic anal fissure. Diseases of the Colon \& Rectum, 2003; 46(6): 805-808.

Friedrich H, Nada A, Bodmeier R. Solid state and dissolution rate characterization of co-ground mixtures of nifedipine and hydrophilic carriers. Drug Dev Ind Pharm 2005; 31(8): 719-728.

Garbacz G, Golke B, Wedemeyer RS, Axell M, Söderlind E, Abrahamsson B, Weitschies W. Comparison of dissolution profiles obtained from nifedipine extended release once a day products using different dissolution test apparatuses. Eur J Pharm Sci 2009; 38(2): 147 155. DOI: 10.1016/j.ejps.2009.06.010

Gohel MC, Sarvaiya KG, Mehta NR, Soni CD, Vyas VU, Dave RK. Assessment of similarity factor using different weighting approaches. Dissolut Technol 2005; $22-27$.

Higuchi T. Mechanism of sustained-action medication. Theoretical analysis of rate of release of solid drugs dispersed in solid 
matrices. J Pharm Sci 1963; 52: 1145-1149.

Hixson AW, Crowell JH. Dependence of reaction velocity upon surface and agitation: theoretical considerations. Ind Eng Chem 1931; 23: $923-931$.

Khan A, Bomminayuni EP, Bhat A, Faucett J, Brown WA. Are the colors and shapes of current psychotropics designed to maximize the placebo response? Psychopharmacology (Berl), 2010; 211(1): 113 - 22. DOI: $10.1007 / \mathrm{s} 00213-010-1874-\mathrm{z}$

Korsmeyer RW, Gurny R, Doelker E, Buri P, Peppas NA. Mechanism of solute release from porous hydrophilic polymers. Int $\mathrm{J}$ Pharm 1983; 15: 25 - $35 . \quad$ DOI:10.1016/0378-5173(83)90064-9

Moore JW, Flanner HH. Mathematical comparison of dissolution profiles. Pharm Tech 1996; 20(6): 64-74.

Nagai N, Murao T, Inubuse R, Konishi N, Ito Y. Quality assessment for sustained release pharmaceutical preparations by dissolution test using microdialysis-HPLC method. Yakugaku Zasshi, $2011 ; 131(4): 621-628$.

Osei-Asare C, 2013. In vitro dissolution of sustained-release nifedipine brands marketed in the Kumasi metropolis. MPhil (Pharmaceutics) thesis. Kwame Nkrumah University of Science and Technology, Kumasi, Ghana, 136p.

Oyeniyi YJ, Ayorinde JO. Pharmaceutical evaluation of some commercial brands of nifedipine (20mg) sustained release tablets, marketed in commercial city of Kano. International Journal of Biology, Pharmacy and Allied Sciences, 2012; 1(4): 585 - 593.

Peppas NA. Analysis of Fickian and non-Fickian drug release from polymers. Pharm Acta Helv1985; 60(4): 110-111.

Salomon JL, Doelker E. Effect of drug and polymer ratio in low-milligram potency formulations. J Pharm Sci 1980; 55: 174.

Sayar E, Sahin S, Cevheroglu S, Atilla A. Comparison of dissolution profiles of two commercially available cotrimoxazole tablets. FABAD J Pharm Sci 2008; 33: 87 - 94.

Shah VP, Tsong Y, Sathe P, Liu JP. In vitro dissolution profile comparison - statistics and analysis of the similarity factor, $\mathrm{f}_{2}$. J Pharm Res 1998; 15(6): 889 - 896.
Siepmann J, Kranz H, Peppas NA, Bodmeier R. Calculation of the required size and shape of hydroxypropyl methylcellulose matrices to achieve desired drug release profiles. Int J Pharm 2000; 201(2): 151-164.

Simon A, Levenson J. Clinical use of nifedipine GITS in the treatment of hypertension: an overview. Expert Opinion on Pharmacotherapy, 2003; 4(1): 95 - 106. DOI: 10.1517/14656566.4.1.95

Soons PA, Schoemaker HC, Cohen AF, Breimer DD. Intraindividual variability in nifedipine pharmacokinetics and effects in healthy subjects. J Clin Pharmacol 1992; 32: 324 - 331. DOI: 10.1002/j.15524604.1992.tb03843.x

Sweetman SC, 2009 Ed. Martindale: the Complete Drug Reference, $36^{\text {th }}$ ed. Pharmaceutical Press, London.

Teder K, Pepeloshev A, Matto V, Meos A. Pharmacopoeial quality of non-expired and expired nifedipine formulations from Estonian and Russian Federation medicinal products market. Acta Pol Pharm 2013; 70(3): $539-546$.

United States Pharmacopoeia and National Formulary, 2007. United States Pharmacopoeial Convention, Rockville, USA.

Varelas CG, Dixon DG, Steiner CA. Zero-order release from biphasic polymer hydrogels. J Control Release 1995; 34: 185-192.

Wagner JG. 1969. Interpretation of percent dissolved-time plots derived from in vitro testing of conventional tablets and capsules. J Pharm Sci 1969; 58: 1253-1257.

Wang Y, Wang H, Zhan C, Chen J. Comparisons of in vitro dissolution of nifedipine tablets manufactured by different pharmaceutical factories. Pharmaceutical Care and Research, 2012; 12(6): 469 - 472.

\section{How to cite this article:}

Christina Osei-Asare, Samuel Lugrie Kipo, Kwabena OforiKwakye, Mariam El Boakye-Gyasi. Comparative in vitro dissolution of commercially available sustained release nifedipine tablet brands in the Kumasi Metropolis, Ghana. J App Pharm Sci, 2015; 5 (08): 054-060. 